Faculdade

de Ciências Econômicas UFRGS

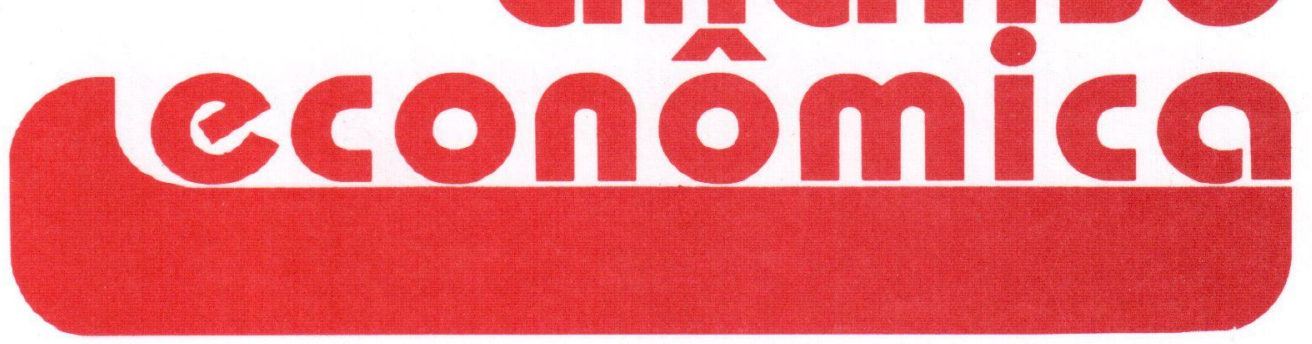

Balança Comercial e Capacidade

Produtiva da Indústria de Transformação

- Flávio Benevett Fligenspan

- Jeferson Luis Bittencourt

Breves Reflexões sobre a Relevância

da História da Teoria Econômica

- Gilberto Tadeu Lima

A Competitividade do Arroz Gaúcho

e seus Condicionantes

- Augusto M. Alvim

- Carlos G. A. Mielitz Netto

Uma Análise da Economia de Ricardo

- Liderau S. Marques Junior

A Estratégia de Substituição de

Importações Revisitada

- Alex Pereira Benício

- Joanílio Rodolpho Teixeira

The Refinements of the Orthodox Macroeconomic Theory and the Post Keynesian Theory

- Fernando Ferrari Filho

Instrumentos de Gestão Ambiental

- Jaildo Santos Pereira

- Vitor Emanuel Tavares

The Economic Implications for

Sustainable Mining

- Dina Franceschi

- James R. Kahn

Mudança Institucional e Estrutural na

Economia Brasileira do Início dos Anos Noventa

- Eduardo Simões de Almeida
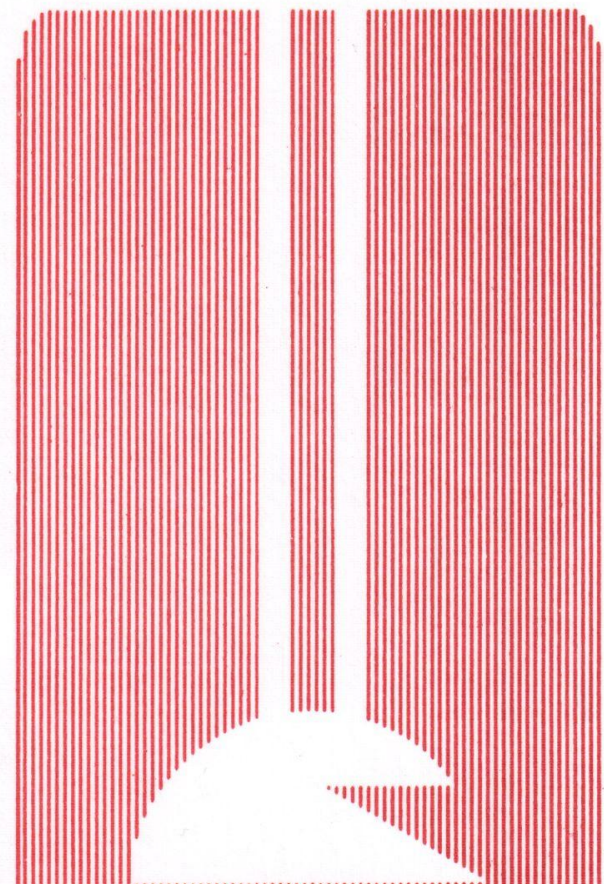

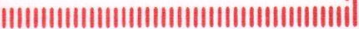
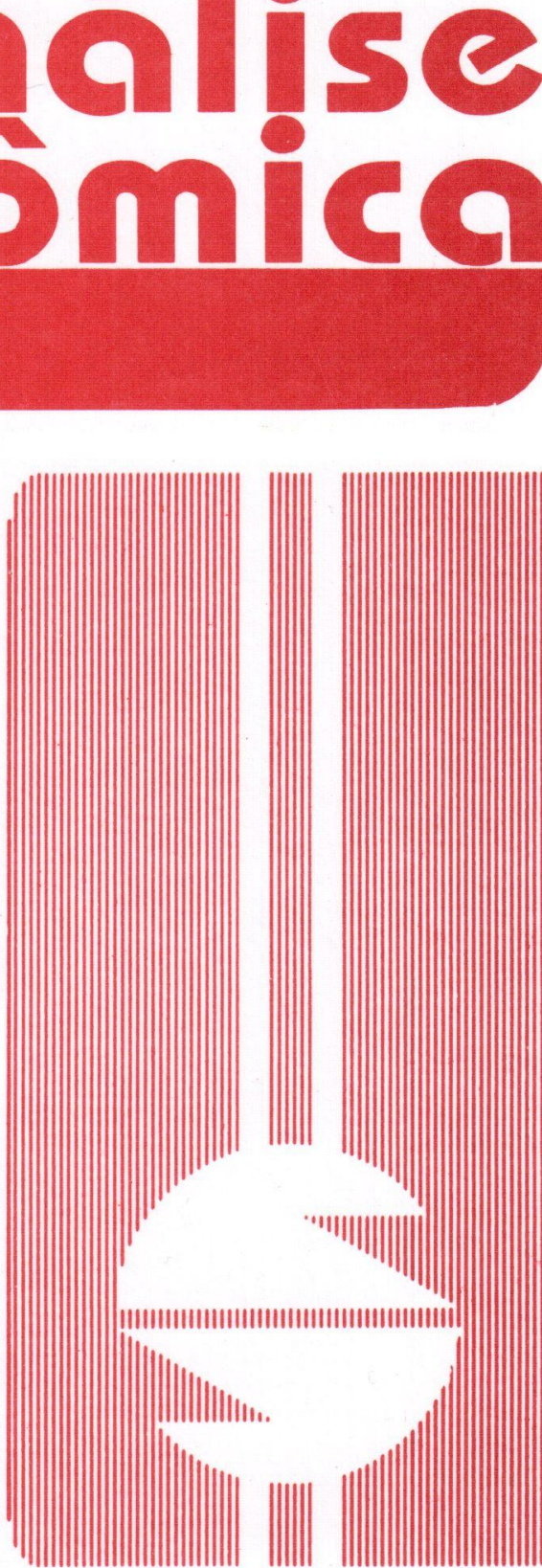
UNIVERSIDADE FEDERAL DO RIO GRANDE DO SUL

Reitora: Prof ${ }^{a}$. Wrana Maria Panizzi

FACULDADE DE CIÊNCIAS ECONÔMICAS

Diretora: Prof . Otilia Beatriz Kroeff Carrion

CENTRO DE ESTUDOS E PESQUISAS ECONÔMICAS

Diretor. Prof. Fernando Ferrari Filho

DEPARTAMENTO DE CIÊNCIAS ECONÔMICAS

Chefe: Prof. Luiz Alberto Oliveira Ribeiro de Miranda

CURSO DE PÓS-GRADUAÇÃO EM ECONOMIA

Coordenador. Prof. Marcelo Savino Portugal

CURSO DE PÓS-GRADUAÇÃO EM ECONOMIA RURAL

Coordenador. Prof. Carlos Guilherme A. Mielitz Netto

CONSELHO EDITORIAL: Achyles B. Costa, Aray M. Feldens, Carlos A. Crusius, Carlos G. A. Mielitz Netto, Eduardo A. Maldonado Filho, Eduardo P. Ribeiro, Eugênio Lagemann, Fernando Ferrari Filho, Gentil Corazza, Marcelo S. Portugal, Nali J. Souza, Otília B. K. Carrion, Paulo A. Spohr, Paulo D. Waquil, Pedro C. D. Fonseca, Roberto C. Moraes, Ronald Otto Hillbrecht, Stefano Florissi, Eleutério F. S. Prado (USP), Fernando H. Barbosa (FGV/RJ), Gustavo Franco (PUC/RJ), João R. Sanson (UFSC), Joaquim P. Andrade (UnB), Juan H. Moldau (USP), Paul Davidson (Univ. of Tennessee), Werner Baer (Univ. of lllinois).

COMISSÃO EDITORIAL: Eduardo Augusto Maldonado Filho, Fernando Ferrari Filho, Gentil Corazza, Marcelo Savino Portugal, Paulo Dabdab Waquil; Roberto Camps Moraes.

EDITOR: Gentil Corazza

EDITOR ADJUNTO: Pedro Silveira Bandeira

SECRETARIA: Fábio Sparremberger. Revisão de textos: Vanete Ricacheski.

FUNDADOR: Prof. Antônio Carlos Santos Rosa

Os materiais publicados na revista Análise Econômica são da exclusiva responsabilidade dos autores. É permitida a reprodução total ou parcial dos trabalhos, desde que seja citada a fonte. Aceita-se permuta com revistas congêneres. Aceitam-se, também, livros para divulgação, elaboração de resenhas e recensões. Toda correspondência, material para publicação (vide normas na terceira capa), assinaturas e permutas devem ser dirigidos ao seguinte destinatário:

PROF. GENTIL CORAZZA

Revista Análise Econômica - Av. João Pessoa, 52 CEP 90040-000 PORTO ALEGRE - RS, BRASIL 


\title{
UMA ANÁLISE DA BALANÇA COMERCIAL PELA ÓTICA DA CAPACIDADE PRODUTIVA DA INDÚSTRIA DE TRANSFORMAÇÃO ${ }^{1}$
}

\author{
Flávio Benevett Fligenspan \\ Jeferson Luis Bittencourt
}

\section{SINOPSE}

Este trabalho se propõe a apontar a questão do saldo comercial como uma das principais barreiras ao crescimento econômico brasileiro. Dentro deste escopo, ao contrário da investigação dos problemas relacionados à taxa de câmbio, optou-se por verificar o papel desempenhado pela capacidade instalada da industria de transformação na determinação dos saldos comerciais, seguindo, com isso, as linhas gerais da política comércio exterior pós-Plano Real. Dessa forma, inicialmente, se traça um perfil da relação entre as duas variáveis, com uma breve revisão da abordagem de outros autores sobre o tema, posteriormente é feita uma identificação dos deslocamentos da série histórica que representa a relação, encerrando-se com uma análise dos períodos identificados e com as conclusões obtidas com o trabalho
Cód. AEA:
Palavras-chave: capacidade instalada da indüstria, saldo comercial, variáveis dummies.

\begin{abstract}
This paper in tends to point out the balance of trade as one of the main barriers to the economic growth of Brazil. However, instead of inquiring in to the problems related to the exchange rates, it focuses on the role of the installed capabilities of the secondary sector and it determines the commercial deficit. This leads to an analysis at the Brazilian international trade policy in the period following Plan Real. Therefore, the paper establishes the relationship between these to variables with a brief overview of the different approaches taken by other authors about this subject. Secondly, the paper identifies the variations of the time series that describe the relationship between commercial deficit and the secondary sector. Finally, it analyses the identified periods with the conclusions reached in the work.
\end{abstract}

AEA Code:

Key-words: installed capabilities, balance of trade, variables dummies.

${ }^{1}$ Este artigo è baseado no capítulo 2 de Bittencourt (1997), monografia classificada em $3^{\circ}$
lugar no XI Prêmio Monografias, do Conselho Regional de Economia da 4 a Região/RS. $^{\text {R }}$.
Os autores agradecem o apoio do Prof. Eduardo Pontual Ribeiro para a solução das
questões econométricas do trabalho. ANÁLISE ECONÓMICA ANO 17 N. 31 Março/99 p. 5-25 


\section{1 - INTRODUÇÃO}

A crise da divida externa, da passagem dos anos 70 para os 80 , deixou exposta a principal fragilidade do modelo de crescimento brasileiro vigente até então: a dependência excessiva do Estado, principalmente quando se tratava do provimento de setores novos na economia. A falência do Estado brasileiro, no que se refere ao impulso direto ao crescimento econômico, num cenário em que nenhum outro agente tivesse maturidade suficiente para assumir seu lugar, acabaria fazendo com que a década de 80 ficasse conhecida como "década perdida".

Em função disso, desde o final da década de 70 até 1994, quando foi implantado o Plano Real, a discussão sobre crescimento econômico no Brasil esteve condicionada à necessidade de se recuperar a estabilidade econômica, para que se pudesse voltar a crescer.

Atualmente, no entanto, um dos fatores que mais tem condicionado as taxas de crescimento da economia brasileira, juntamente com o ritmo de aumento da dívida interna, tem sido os resultados da Balança Comercial que, desde o início do Plano, apresentam-se cadentes. Como se sabe, o resultado da Balança Comercial é extremamente vinculado ao comportamento da taxa de câmbio real. Porém, dado que a condução recente desta variável não sugere uma solução para o problema do saldo comercial a curto prazo, abordagens alternativas dessa questão passam a ganhar importância.

A própria política de comércio exterior, que no início do Plano foi uma das causadoras do agravamento do problema, tem sido mais intensamente acionada como instrumento alternativo. Contudo as novas regras do comércio internacional têm evoluído no sentido de impor um afastamento cada vez maior da estratégia da década de 80 , de geração de resultados positivos pelo uso de restrições às importações e incentivos às exportações que, mesmo constituindo-se como uma alternativa espúria em termos de livreconcorrência, daria um passo importante no sentido do equacionamento do problema da Balança Comercial.

Outro caminho alternativo, pelo qual a política econômica também já deu alguns passos, é o do aumento da competitividade do produto nacional, de forma que se viabilizasse uma maior penetração deste no mercado mundial. Para percorrer este caminho, é necessário envolver de maneira direta o setor industrial como peça-chave na resolução deste problema. Num contexto de globalização, a indústria cumpre uma função relevante como exportadora, e também passa a desempenhar um papel de destaque em relação à capacidade de competir internamente com os produtos importados. 
Com base nestas constatações, deseja-se abordar neste trabalho a relação entre a Balança Comercial e o desempenho da indústria brasileira, no intuito de apontar um fator endógeno que pode estar contribuindo para os desequilíbrio das contas externas. Ou seja, percebendo-se como verdadeira a idéia de que o saldo comercial é uma variável decisiva na história do processo de crescimento brasileiro ${ }^{2}$, deseja-se investigar a relação entre esta variável e a capacidade produtiva da indústria de transformação, indicando, se possível, a forma e o comportamento dessa relação.

Por fim, deve-se salientar, mais uma vez, que a abordagem da relação saldo da Balança Comercial versus utilização da capacidade instalada da indústria desempenha papel central na questão que se discute em nível nacional: o crescimento econômico. O que se deseja é contribuir para esta discussão, mostrando que é possível tratá-la sem necessariamente exigir mudanças profundas na política cambial.

Este trabalho contempla, além dessa introdução, a apresentação da metodologia usada para a identificação da relação entre as variáveis que representam a utilização da capacidade instalada da indústria e o saldo comercial e quatro outros itens. No primeiro se traça um perfil da relação entre as duas variáveis, com uma breve revisão dả abordagem de outros autores a respeito da relação entre o comportamento da indústria e os determinantes do saldo comercial. O segundo se propõe à identificação dos deslocamentos da série histórica que representa a relação central desse estudo. No terceiro item faz-se uma análise dos períodos identificados e, por fim, apresentam-se as conclusões obtidas com o trabalho.

\section{2 - METODOLOGIA}

Para que fosse possivel realizar este estudo, tomou-se a variável Utilização da Capacidade Instalada da indústria de transformação (UCI), fornecida trimestralmente, para o mês de coleta das informações, em termos percentuais, pela Sondagem Conjuntural, realizada pela Fundação Getúlio Vargas e publicada na revista Conjuntura Econômica. Já os dados relativos ao saldo da Balança Comercial foram obtidos na mesma publicação, e têm como fonte o Instituto Brasileiro de Economia e o Ministério da Indústria, Comércio e Turismo.

Como a variável explicativa, $\mathrm{UCl}$, é coletada para meses específicos, quais sejam, janeiro, abril, julho e outubro, foi necessário que a variável explicada fosse tomada para os mesmos períodos. Para as regressões, utilizando-se os dados dessazonalizados apresentados no Gráfico 1, foram

2 Para verificar o comportamento da Balança Comercial no Brasil durante o Plano de Metas, o II PND e o Plano Real, ver Bittencourt (1997). 
tomadas apenas as informações de saldo comercial correspondentes aos meses de coleta das informações de $\mathrm{UCl}$, perfazendo com isso um total 68 observações, entre janeiro de 1980 e outubro de 1996.

No Gráfico 1, cuja apresentação visa elucidar o comportamento das variáveis no periodo analisado, o saldo da Balança Comercial está representado pela linha cheia. Os dados que serviram de base para a elaboração desta foram tomados mensalmente desde janeiro de 1980 até dezembro de 1996. Já a UCl, tomada para o mesmo período, cujos dados disponiveis têm periodicidade trimestral, está representada pela série de pontos. Esta forma de apresentação em pontos representa melhor o comportamento da variável, visto que, se estes pontos fossem unidos, estar-se-ia inferindo um comportamento entre os periodos de coleta dos dados que muito provavelmente não corresponderia à realidade. São apresentados, também, os polinômios que representam as linhas de tendência das séries apresentadas.

Gráfico 1 - Saldo da balança comercial (mensal) e UCl da indústria de transformação (trimestral) - série dessazonalizada - 1980/1996

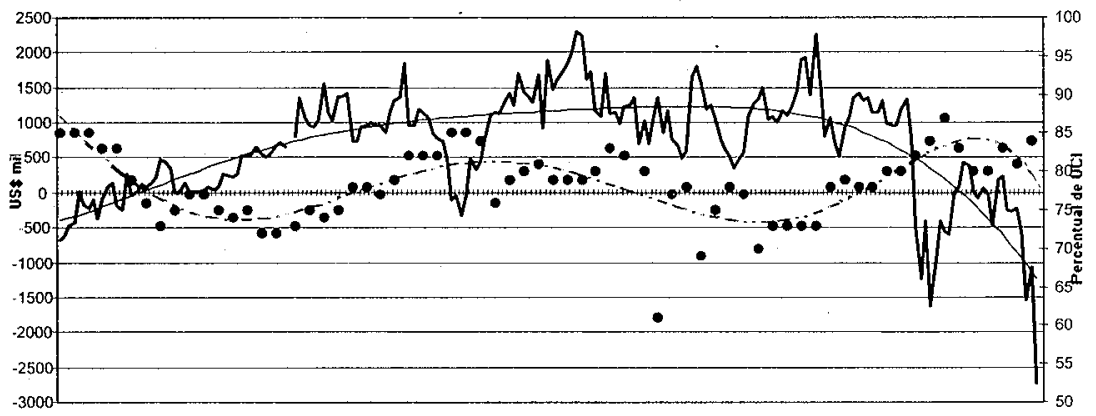

Fonte dos dados brutos: Conjuntura Econômica. Sondagem Conjuntural e Conjuntura Estatística, vários nùmeros (1980-1997).

Para estabelecer a relação entre as duas variáveis, realizaram-se regressões lineares simples, através do método dos Mínimos Quadrados Simples. Como o que se deseja obter é a relação entre apenas duas variáveis ou, mais especificamente, o papel da UCl na determinação do saldo comercial, a regressão simples foi adotada como instrumento capaz de atingir tal objetivo. Foram introduzidas variáveis dummies nestas regressões, inicialmente com o intuito de mostrar a existência de diferenças substanciais entre determinados períodos, que poderiam ser consideradas deslocamentos na série. Posteriormente, outras regressões, também inclu- 
indo variáveis dummies, foram realizadas, desta vez com o intuito de caracterizar melhor os diferentes períodos da série.

Cabe reafirmar que os dados de Utilização da Capacidade Instalada, os dados referentes ao saldo da Balança Comercial, como já havia sido referido acima, foram dessazonalizados, com o intuito de tornar possível a análise da série para qualquer corte temporal desejado.

\section{3 - PERFIL DA RELAÇÃO ENTRE A UCI E O SALDO COMERCIAL}

De acordo com o que foi exposto anteriormente, o estudo da relação que é tema deste trabalho visa contribuir para a discussão sobre o crescimento econômico, através da identificação de um fator endógeno que pode estar promovendo o agravamento do problema da Balança Comercial do país. Dentro dessa idéia, Malan e Bonelli (1976) apresentam um estudo sobre as origens endógenas da desaceleração do ritmo de crescimento da economia brasileira naquela época. Nesse trabalho os autores procuram, entre outras coisas, pela investigação dos ciclos produtivos e da utilização da capacidade instalada da indústria, razões dentro modelo de crescimento brasileiro que, aliadas ao contexto de crise do petróleo, ajudam a explicar os substanciais déficits comerciais de 1974 e 1975.

É preciso que se considere, no entanto, que a relação entre os resultados obtidos no setor externo da economia brasileira e o nivel de utilização da capacidade produtiva industrial, analisada de maneira mais explicita que em Malan e Bonelli (1976), possui referência na literatura especializada. Castro e Souza (1985) apresentam o tipo de comportamento esperado da razão entre o Saldo de Transações Reais e o PIB, por um lado, e a utilização da capacidade, por outro. A figura que estabelece esta relação é apresentada adiante.

Sem entrar no mérito da discussão da posição das curvas neste periodo, o que é feito com propriedade no referido texto, mesmo porque o periodo tratado pelos autores é diferente do que será tratado aqui, são imprescindiveis algumas considerações sobre o formato das curvas apresentadas.

A inclinação negativa das curvas da figura abaixo é uma decorrência da idéia de que aumentos do nivel de atividade, que iriam se refletir numa maior utilização da capacidade, imporiam uma queda na relação STR/PIB, que ocorreria em função de acréscimos de importações e reduções nas exportações, com o intuito de atender o mercado interno. É importante ressaltar que o movimento esperado descrito acima, tanto para as importações como para as exportações, afetaria o numerador e o denominador da relação $S T R / P I B$ no mesmo sentido, porém com mais ênfase o primeiro, em função do peso do saldo comercial no STR, provocando, então, a queda referida. 
Quanto ao aumento da inclinação das curvas, quando a utilização da capacidade se aproxima dos seus limites superior e inferior, Castro e Souza (1985) acrescentam que, quando esta variável se aproxima de $90 \%$, o coeficiente marginal de importações se eleva rapidamente, refletindo uma rigidização da oferta doméstica, face a uma demanda ainda em expansão. Isto faz com que o saldo comercial apresente uma forte queda, quando se caminha em direção à plena utilização da capacidade.

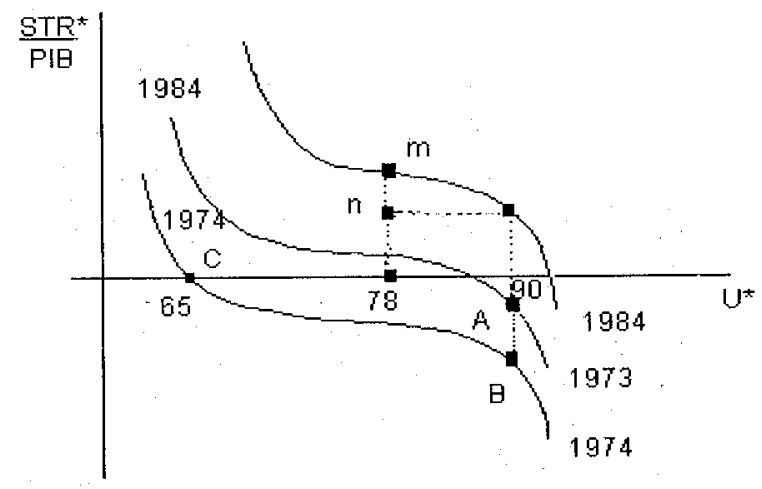

Nota: $\operatorname{STR}^{*}=$ Saldo de Transações reais ( balanço de bens e serviços não fatores); $\mathrm{U}^{*}=$ Utilização da capacidade

Figura 1 - Curva de saldo das transações reais (Castro e Souza, 1985)

De forma análoga, quando a retração da demanda interna se acentua, a utilização da capacidade cai abaixo de um determinado nível e, isto, promove um forte deslocamento da oferta para o mercado externo. Dessa forma, a rápida expansão das exportações (repelidas pelo mercado interno), aliada à falta de demanda por importações, justificam a elevação acentuada do saldo comercial, puxando rapidamente para cima a relação STR/PIB.

Ainda no que se refere a relação negativa entre a $U C \mathrm{Cl}$ e os resultados da Balança Comercial, cabe uma referência ao trabalho de CNI e CEPAL (1997). Este, ao estudar os investimentos na indústria brasileira no periodo 1995 a 1999, aponta que as empresas analisadas esperam que uma das características destes investimentos seja o expressivo aumento da capacidade produtiva. Levando-se em consideração esta característica e que, de acordo com os autores, é provável que "(...) os investimentos determinados prioritariamente pela expansão do mercado doméstico dão à indústria condições de competitividade para enfrentar adequadamente as importações e expandir aceleradamente as exportações"(CNI e CEPAL, 1997, p.10), percebe-se aí mais uma inferência sobre um possivel perfil da relação entre a 
capacidade instalada da indústria e os reflexos do nível de utilização dessa sobre o saldo comercial.

No entanto, estas referências sobre um possível perfil da relação entre a $\mathrm{UCl}$ e o saldo comercial podem ser contraposta por outra idéia presente na literatura nacional. No que se refere à associação positiva entre políticas visando um comércio exterior mais aberto e uma maior eficiência produtiva ou uma maior produtividade, há uma hipótese sobre esta relação que está diretamente ligada às variáveis abordadas neste estudo.

A hipótese baseia-se na associação positiva entre o crescimento da produção e o crescimento da produtividade (Lei de Verdoorn, quando em termos de produtividade do trabalho), conforme apresentado por Bonelli (1994). Bastante aplicável a indústrias manufatureiras, este argumento está calcado na existência de economias de escala, já que a expansão do mercado através do comércio exterior pode gerar aumentos de produtividade e redução dos custos. Mesmo que este argumento seja normalmente usado no caso da expansão das exportações, ele também é aplicado ao caso das substituições de importações, quando o resultado final depende do tamanho e da estrutura do mercado interno.

"Assim, uma política orientada para fora é provavelmente relacionada à maior eficiência devido aos efeitos de um mercado ampliado para as exportações, o qual permite aumentos na utilização da capacidade e economias de escala derivadas da especialização. Deve-se ainda levar em conta que o crescimento no uso de fatores produtivos (particularmente utilização da capacidade) pode também depender da política comercial. Isto é, os efeitos desta sobre a eficiência-produtividade são tanto diretos (aumento na competição e na eficiência dos recursos utilizados), quanto indiretos (aumento na utilização de capacidade, elevação de investimento incorporando novas tecnologias, aumento na aquisição de habilidades);" (Bonelli, 1994, p.18)

Em síntese, este argumento se contrapõe à idéia anteriormente apresentada, de que a um aumento da demanda, que promova um aumento da utilização da capacidade, corresponderia uma queda das exportações, em função de um redirecionamento da oferta para atender o consumo interno. Este argumento apresenta uma outra situação, na qual o aumento da produção (mesmo que para atender o mercado externo), e conseqüentemente, o aumento da $\mathrm{UCl}$, desde que ainda não se tenha chegado à plena utilização, pode promover ganhos de escala, e com isso, um aumento das exportações. Além disso, ele também incorpora efeitos do lado das importações, uma vez que a entrada de bens importados, aumentando a disputa pelo mercado interno, também promove uma busca pela eficiênciaprodutividade. 
Ainda que o argumento da Lei de Verdoorn coloque-se em oposição ao anteriormente estabelecido, deve-se dizer que ele não tem força suficiente para negá-lo. Isto é, cada caso concreto gerará um resultado líquido especifico a partir dessas duas tendências opostas.

\section{4 - AS “QUEBRAS” DO PERÍODO 1980-1996}

Para que se possa identificar a relação propriamente dita entre o saldo comercial e a $\mathrm{UCl}$, é necessário que se proceda à divisão da série de dados obtida em períodos relativamente semelhantes a serem analisados separadamente. Com este intuito, serão apresentados os resultados de regressões lineares, originárias de uma primeira série de exercícios realizados através do Método dos Mínimos Quadrados Simples.

A série analisada foi a mesma apresentada no Gráfico 1, ou seja, de 1980 a 1996. Com o objetivo de identificar os períodos semelhantes, usa-se o Gráfico 2, que representa a relação entre a UCI média anual da indústria de transformação e os resultados anuais da Balança Comercial, e divide-se a série de maneira a agrupar os anos com características comuns. O primeiro período, representado pelos quadrados marcados com asteriscos, corresponde aos anos de 1980 a 1983. Este é considerado o período de maturação dos investimentos do II PND. O segundo período, caracterizado como de relativo fechamento da economia e geração de expressivos superm ávits comerciais, vai de 1984 a 1989, e é representado pelos círculos cheios. Os quadrados cheios representam o periodo de abertura da economia e vão de 1990 a 1994. Sobre os anos de 1995 e 1996 não se tem uma idéia clara; se fazem parte ainda da mesma estrutura do período anterior, ou se estariam inaugurando uma nova fase nesta relação. Por isso, inicialmente ficam em uma divisão à parte, estando representados pelos círculos vazados.

Gráfico 2 - Média anual UCl versus saldo da balança comercial - 1980/96 


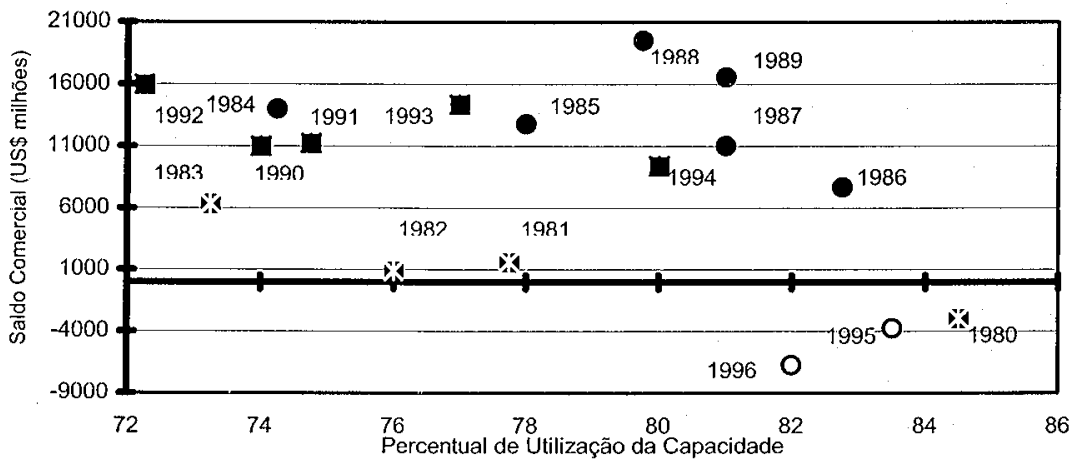

Fonte dos dados brutos: Conjuntura Econômica. Sondagem Conjuntural e Conjuntura Estatistica, vários números (1980-1997).

Com o objetivo de representar os períodos nos quais ocorrem deslocamentos na relação, como foi dito anteriormente, foram incluídas no modelo variáveis dummies de intercepto e de inclinação. É importante salientar que a inclusão dessas variáveis não tem como principal objetivo dar maior poder de explicação ao modelo; o que se deșeja com a sua utilização é averiguar se, em determinados períodos, há deslocamentos (ou "quebras") na série apresentada. A seguir são apresentados os resultados das regressões.

\section{1 - 1980-1996}

Utilizando-se inicialmente a série completa, incluiu-se no modelo duas variáveis dummies de intercepto, uma para o período 1984-1989 (D1) e outra para o período 1990-1996 (D2). Os resultados obtidos com a regressão estão apresentados no Anexo B.

Como se pode perceber, os resultados dos testes $t$ de Student e do valor-P, ao nível de confiança de $95 \%$, garantem que não se pode negar que os parâmetros não são significativamente diferentes de zero. Além disso, pelo teste $t$ de Student, percebe-se também que não se pode negar, no que se refere ao parâmetro de inclinação ( $(\cup \mathrm{Cl})$, que este é menor que zero. Logo, confirma-se a idéia de que, ao nível de confiança apresentado acima, a relação entre a $\mathrm{UCl}$ e a Balança Comercial é negativa para este período, ou seja, aos aumentos da $\mathrm{UCl}$ corresponderiam quedas no saldo da Balança Comercial.

Os resultados das dummies de intercepto adotadas indicam que, entre os períodos de 1980-1983 ( $1^{\circ}$ período) e 1984-1989 ( $2^{\circ}$ período), há um deslocamento paralelo da curva para cima, ficando o período $1990-1996$ (3 
período) em uma situação intermediária aos dois primeiros. Por estes resultados, pode-se afirmar que houve um aumento dos saldos comerciais correspondentes a uma mesma $\mathrm{UCl}$ da indústria de transformação, entre o $1^{\circ}$ e o $2^{\circ}$ períodos, provavelmente decorrente da maturação dos investimentos do II PND e da fase de relativo fechamento da economia brasileira. A partir do $3^{\circ}$ período, com a falta de investimentos decorrentes dos problemas da economia na década de 80 e com a abertura comercial, a estrutura produtiva deixou de ser capaz de gerar saldos comerciais positivos com tanta facilidade como no período anterior, deslocando-se então a curva para baixo.

Ainda que se considere que o deslocamento para cima da curva do $1^{\circ}$ para o $2^{\circ}$ períodos, em função do deslocamento do seu intercepto, implique um maior saldo comercial autônomo, é importante deixar claro que não se pode dizer que a UCl perde poder de explicação em relação ao comportamento da Balança Comercial. Esta afirmação poderia ser feita, somente se fosse considerada a variação dos resíduos, que se configuram na parte das variações do saldo comercial que ocorrem em função do comportamento de outras variáveis.

Quanto à alteração no intercepto da curva de 1980-1983 para 19841989 , pode-se dizer ainda que a um mesmo percentual de UCI na indústria de transformação, no $2^{\circ}$ período, os resultados da Balança Comercial são melhores que no $1^{\circ}$, ou seja, pode-se obter um mesmo saldo comercial com um nivel menor de $\mathrm{UCl}$. Isto implica que um aumento da demanda no $1^{\circ}$ período, que provocasse um incremento do nivel de utilização da capacidade, apresentaria uma redução relativa do saldo comercial maior do que se este incremento de $\mathrm{UCl}$ se desse no $2^{\circ}$ período. Entre o $2^{\circ}$ e o $3^{\circ}$ períodos, a análise do deslocamento da curva é a mesma feita para o $1^{\circ}$ e $2^{\circ}$ períodos, porém a diferença entre as inclinações das curvas do $1^{\circ}$ e $2^{\circ}$ períodos é maior do que a diferença entre as inclinações do $2^{\circ}$ e $3^{\circ}$ períodos.

Cabe ressaltar que a utilização conjunta de variáveis dummies de inclinação e intercepto não obteve um resultado satisfatório, já que, pelos testes, não se pôde negar que os parâmetros das dummies são significativamente diferentes de zero, ao nível de confiança estipulado acima. Além disso, percebe-se que os coeficientes de correlação (R2), ficando em torno de $59 \%$ ( $57 \%$ no caso do R2 ajustado pelo tamanho da amostra), expressam uma razoável capacidade de explicação do modelo, considerando que uma quantidade expressiva de variáveis afetam o saldo comercial e, no caso da regressão aqui calculada, trata-se de apenas uma.

Mesmo sendo também aplicáveis como teste para verificar a existência de "quebras" na série analisada, os resultados obtidos com a utilização da dummy de inclinação não devem ser considerados. Como o modelo com a inclusão simultânea de dummies de inclinação e intercepto não foi conside- 
rado válido, a utilização de dummies de inclinação para um período amplo ficou prejudicada. Uma vez que a inclusão de dummies de inclinação seria feita para anos nos quais a maioria dos saldos comerciais eram superiores aos verificadas no período 1980-1983, necessariamente a inclinação da curva representativa deste período teria que ser menor, pois ela teria sua declividade reduzida, já que o intercepto era o mesmo do período anterior e a sua função seria captar estas situações de melhores resultados da Balança Comercial:

Como a informação mais importante que a dummy de inclinação traria ${ }^{3}$, sofreu este viés e apontaria sempre no mesmo sentido, enquanto se tratassem de períodos de melhores saldos comerciais que os iniciais, optou-se por não usar este artifício para analisar a inclinação das curvas nos períodos considerados. Ainda assim, a utilização das dummies de inclinação confirmaram a existência das "quebras", que já haviam sido apontadas pela utilização das dummies de intercepto.

\section{2 - 1980-1994}

Excluindo-se da série completa os anos de 1995 e 1996, com o intuito de testar a sua influência sobre o modelo, obtiveram-se resultados semeIhantes aos da série 1980-1996. Tanto com a inclusão de dummies de intercepto, como de dummies de inclinação, os testes validaram a existência de todos os parâmetros, a 95\% de confiança, confirmando-se, também, a inclinação negativa da curva e os deslocamentos nos períodos 1984-1989 e 1990-1994.

O coeficiente de correlação subiu em relação à série analisada anteriormente, considerando a inclusão das dummies de intercepto, passando de um patamar de $60 \%$ para $65 \%{ }^{4}$, indicando um maior poder de explicação do modelo. Também quanto às posições das curvas, não houve alterações, permanecendo o último período (1990-1994) em uma posição intermediária em relação aos outros dois períodos.

Mesmo que a regressão feita para a série 1980-1994 tenha apresentado um maior coeficiente de correlação, não se pode dizer que a exclusão dos dois últimos anos da primeira série tenha provocado uma diferença substancial. Baseando-se nos intervalos de confiança dos parâmetros (estes intervalos são apresentados nas quatro últimas colunas do último quadro de resultados de cada regressão, no Anexo B), percebe-se que há um cruzamento deles nas séries 1980-1996 e 1980-1994. Esta constatação

\footnotetext{
${ }^{3} \mathrm{Em}$ comparação com a dummy de intercepto, a dummy de inclinação poderia informar a diferença na elasticidade- $\mathrm{UCl}$ do saldo comercial entre os periodos.

${ }^{4} \mathrm{O}$ resultado do $\mathrm{R}$-quadrado ajustado pelo tamanho da amostra, que ficava em torno de $57 \%$, considerando o periodo de $1980-1996$, passou para um patamar de $63 \%$, se se desconsiderar os dois últimos anos da série.
} 
aponta para uma potencial igualdade de todos os parâmetros da série completa, o que revela que os anos de 1995 e 1996 se apresentam ainda explicados pelo modelo que incluía os anos 1980-1994.

\section{5 - A RELAÇÃO SALDO COMERCIAL X UCI NOS PERÍODOS SELECIONADOS}

Pelos resultados obtidos com o estudo anterior, foi possivel dividir a série total de acordo com o exercício realizado com a inclusão das variáveis dummies. Tendo sido testados os parâmetros das variáveis dummies para os períodos 1984-1989 e 1990-1996, e considerando-se que, pelos resulta* dos obtidos, não se pôde negar a existência dos deslocamentos na série nestes períodos, adotou-se a seguinte divisão: 1980-1983, 1984-1989 e 1990-1996.

O exercício apresentado neste subitem consiste em fazer uma regressão para cada periodo selecionado, devido à impossibilidade verificada no exercício anterior, de se incluir no modelo, simultaneamente, dummies de intercepto e inclinação. Realizando-se a regressão para cada um destes periodos, espera-se obter informações mais confiáveis e expressivas da realidade, pois, além de se analisar períodos mais homogêneos, podem-se verificar as alterações nas inclinações das curvas.

\section{1 - 1980-1983}

O periodo de 1980-1983, como foi visto anteriormente, correspondeu ao momento em que maturavam os investimentos realizados no II PND. Na realidade, neste período já estavam entrando em funcionamento alguns destes projetos e, em 1984, como visto em Castro (1985), a capacidade de produção da indústria nacional já estava em um patamar mais alto do que nos periodos anteriores. Com o primeiro período limitado em 1983, é possível verificar os patamares das variáveis utilização da capacidade produtiva e saldo comercial antes da entrada em funcionamentos dos projetos do II PND.

A regressão simples, como se sabe, é um instrumento não muito utilizado, quando se deseja explicar o comportamento de uma variável. No entanto, como o objetivo aqui é mostrar a influência de uma variável (UCl) no comportamento de outra (resultado da Balança Comercial), ou seja, uma análise parcial, este instrumento mostra-se eficaz. As informações mais importantes que devem ser tomadas são aquelas referentes à relação entre a utilização da capacidade instalada e o saldo comercial. Este critério torna-se adequado, uma vez que o modelo gerado não será utilizado para se fazer previsões. A seguir, apresenta-se o gráfico para este período, e os resultados da regressão estão no Anexo $B$.

Gráfico 3 - UCl versus saldo da balança comercial - 1980/83 


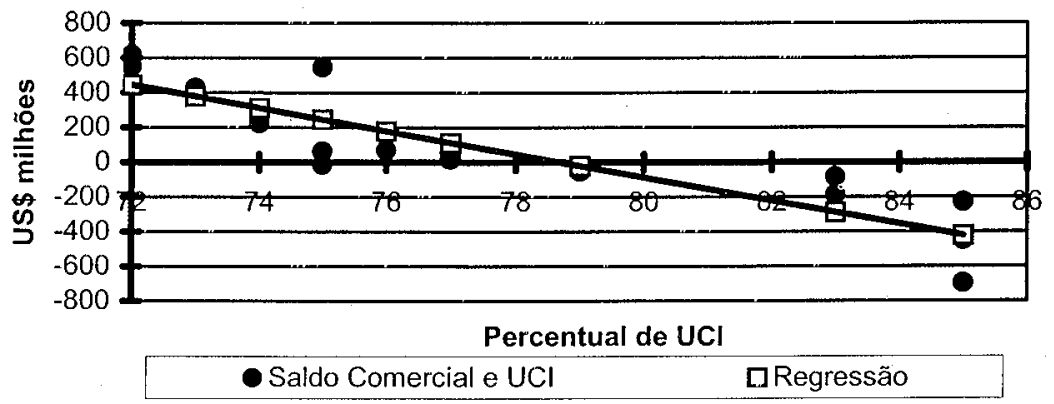

Obs: dados trimestrais dessazonalizados

Fonte dos dados brutos: Conjuntura Econômica. Sondagem Conjuntural e Conjuntura Estatística, vários nümeros (1980-1997).

Dessa forma, deve-se perceber que, como se verificou no item 4, não se pode negar também para este período que a relação entre o nível de $\mathrm{UCl}$ e o saldo da Balança Comercial (dada por $\beta \mathrm{UCl}$ ) é negativa. Isto expressa justamente a idéia de que ao se aumentar a demanda, o que provoca um aumento da $\mathrm{UCl}$, ocorre um aumento das importações, num primeiro momento, com o intuito de atender às necessidade finais e intermediárias e, num segundo momento, como função do aumento de renda. Já o comportamento esperado das exportações é de queda, devido a um deslocamento para o mercado doméstico de produtos outrora destinados ao mercado internacional.

É importante ainda ressaltar que, neste caso, como o número de observações é relativamente pequeno, para considerações sobre o coeficiente de correlação, usou-se o R-quadrado ajustado pelo tamanho da amostra. Este, por levar em consideração os graus de liberdade, apresenta um resultado mais confiável sobre a capacidade do modelo de regressão de explicar o comportamento da variável. Quanto ao resultado obtido, pode-se dizer que, dado que se está utilizando apenas uma variável para explicar o comportamento da Balança Comercial, o coeficiente de correlação ajustado pelo tamanho da amostra superior a $76 \%$ é bastante razoável.

\section{2 - 1984-1989}

Pelos exercícios realizados no item 4, para o período 1984-1989, foi possivel verificar um deslocamento da série em relação ao periodo 1980 1983, uma vez que os testes aplicados aos parâmetros das variáveis dummies confirmam que estes são diferentes de zero, ao nivel de confiança de $95 \%$. De posse desta constatação, realizou-se uma nova regressão linear para este período específico, com a finalidade de suprir a carência decor: 
rente da impossibilidade verificada anteriormente, de se aplicar ao mesmo período variáveis dummies de inclinação e intercepto.

Como se sabe, este período corresponde aos anos em que a inflação foi a maior preocupação da política econômica nacional, sendo que este concentra os principais planos de estabilização da década de 80 . Nestes anos, o volume das importações esteve bastante sujeito a controles administrativos, enquanto as exportações ganharam competitividade em relação ao período anterior, permitindo inclusive um maior saldo comercial com a mesma UCl, como será visto a seguir.

Ao contrário do exercício anterior, no periodo que será considerado aqui, a utilização das variáveis dummies tem um papel muito mais explicativo na regressão. Enquanto para o intervalo de tempo 1980-1996, a preocupação principal era mostrar a existência dos deslocamentos da série, aqui as dummies serão mais relevantes para aumentar o poder de explicação do modelo. Por isso, foi utilizada uma variável dummy de intercepto - que, comparativamente à dummy de inclinação, apresentou melhores resultados -, para captar no modelo o período 1988-1989, caracterizado pelos recordes anuais do saldo comercial. Graficamente, os resultados são apresentados a seguir.

Gráfico 4 - UCl versus Saldo da Balança Comercial - 1984/1989

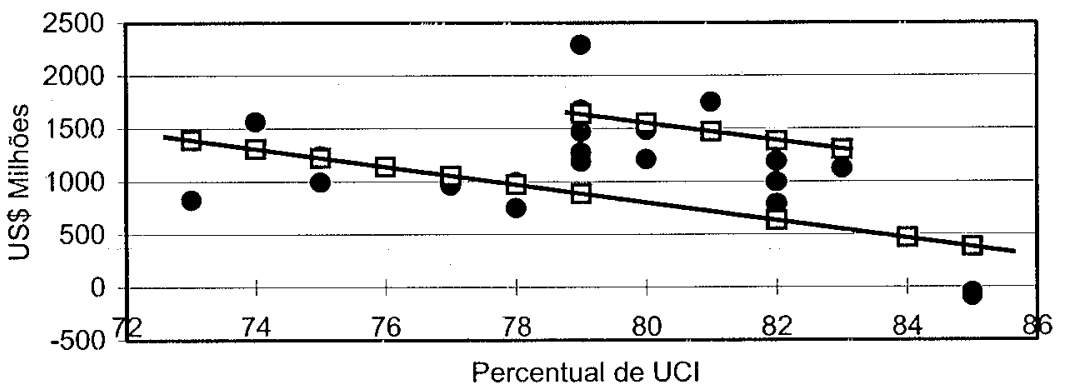

- Saldo Comercial e UCI

$\square$ Reg. dummy intercepto

Obs: dados trimestrais dessazonalizados

Fonte dos dados brutos: Conjuntura Econômica. Sondagem Conjuntural e Conjuntura Estatistica, vários números (1980-1997).

Pode-se ver, tanto pela comparação dos gráficos 3 e 4 , como pelos resultados da regressão (no Anexo $\mathrm{B}$ ), o deslocamento para cima da curva. $\mathrm{O}$ 
intercepto da curva subiu de US $\$ 5,2$ bilhões no período 1980-1983 para US $\$ 7,5$ bilhões no periodo 1984-1989 e US $\$ 8,3$ bilhões, este último pela inclusão da variável dummy. Este deslocamento confirma o que foi expresso acima, ou seja, que o controle das importações e o aumento das exportações, decorrentes da maturação dos investimentos do II PND e das políticas cambiais e comerciais vigentes, elevaram o patamar do saldo comercial brasileiro, de 1980-1983 para 1984-1989. Quanto ao deslocamento do intercepto da curva para 1988 e 1989, parece que, muito mais que os acréscimos de competitividade, a expansão do mercado mundial foi o fator determinante da elevação dos patamares do saldo comercial.

Mesmo que a comparação da inclinação das curvas para os periodos 1980-1983 e 1984-1989 indique que a segunda é mais inclinada que a primeira ou, de outra forma, que às mesmas alterações na $\mathrm{UCI}$ no $2^{\circ}$ período corresponderiam alterações absolutas maiores no saldo comercial que no $1^{\circ}$ período, esta é uma afirmação que não pode ser feita. Novamente, cotejando os intervalos de confiança para os parâmetros de inclinação da duas curvas, percebe-se que estas não são significativamente diferentes entre si. Como o intervalo de confiança da inclinação do período 1984-1989 inclui o intervalo de confiança do mesmo parâmetro para o período que vai de 1980 a 1983, os parâmetros poderiam apresentar uma semelhança muito maior ou até mesmo serem iguais.

Em decorrência disto, é desaconselhável que se faça qualquer afirmação sobre as mudanças na declividade das curvas, ou características do modelo decorrentes delas. Assim, para se inferir, por exemplo, alterações na intensidade da relação entre a indústria e o comércio exterior, o modelo apresentado não é indicado. Deve-se creditar, portanto, como visto acima, a alterações em outras variáveis, o fato da curva ter deslocado o seu intercepto para cima entre 1980-1983 e 1984-1989. Dentre estas, o aumento de competitividade das exportações e o relativo fechamento da economia para as importações parecem ter tido um papel de destaque ${ }^{5}$.

Por fim, quanto à regressão obtida para este período, pode-se dizer que os seus resultados expressam uma parcela menor da realidade, uma vez que o R-quadrado ajustado pelo tamanho da amostra, ficou em pouco mais de $59 \%$. Esta redução na capacidade de explicação do modelo em relação ao período 1980-1983 pode expressar a perda de importância que teve a $\mathrm{UCl}$ na determinação das variações do saldo comercial, em função

\footnotetext{
${ }^{5} \mathrm{O}$ resultado do trabalho de Bonelli (1994) coaduna-se com o exposto acima. Este afirma que a partir de 1985 as exportações brasileiras já estavam perdendo competitividade no mercado internacional. No entanto, aliado ao controle administrativo das importações, a expansão do comércio internacional e, conseqüentemente, dos mercados dos produtos exportáveis brasileiros, teriam provido em grande medida os expressivos resultados da Balança Comercial brasileira neste periodo.
} 
da política de comércio exterior adotada na época, uma vez que os resíduos aumentaram.

\section{$5.3-1990-1996$}

O último periodo para o qual os testes mostraram quebras na série completa, 1990-1996, guarda uma particularidade em relação aos outros períodos analisados. Pela série de regressões realizadas, com e sem a utilização do mês de abril de 1990, verificou-se que este mês tinha um efeito bastante negativo sobre os resultados finais. Isto é uma decorrência do fato de que sobre este mês recaem a maior parte dos efeitos do Plano Collor I.

Em função do confisco por 18 meses dos ativos financeiros privados, este plano teve um efeito bastante negativo sobre a atividade econômica. Ainda que, sobre a variável independente deste modelo, os reflexos tenham sido percebidos por um curto período, a distorção causada pela queda de $80 \%$ para $61 \%$ na $\mathrm{UCl}$ sobre o modelo foi tamanha que justifica a sua exclusão, uma vez que certamente esta variável perdeu uma parte significativa do seu poder de explicação do saldo comercial neste mês.

Assim como foi feito para o período 1984-1989, incluiu-se uma variáve! dummy de intercepto, a fim de captar no modelo o deslocamento da série promovido pelos efeitos do Plano Real. A estabilidade econômica, o aquecimento da economia, a valorização do câmbio e a aceleração no processo de abertura da economia são fatores relacionados entre si, que atuaram diretamente sobre a relação entre o saldo comercial e a $\mathrm{UCl}$, justificando assim a inclusão de uma variável dummy para o período de 1995 e 1996. Como nos casos anteriores, os resultados da regressão estão no Anexo $\mathrm{B}$ e o gráfico da regressão é apresentado a seguir.

Gráfico 5 - UCI versus Saldo da Balança Comercial - 1990/96

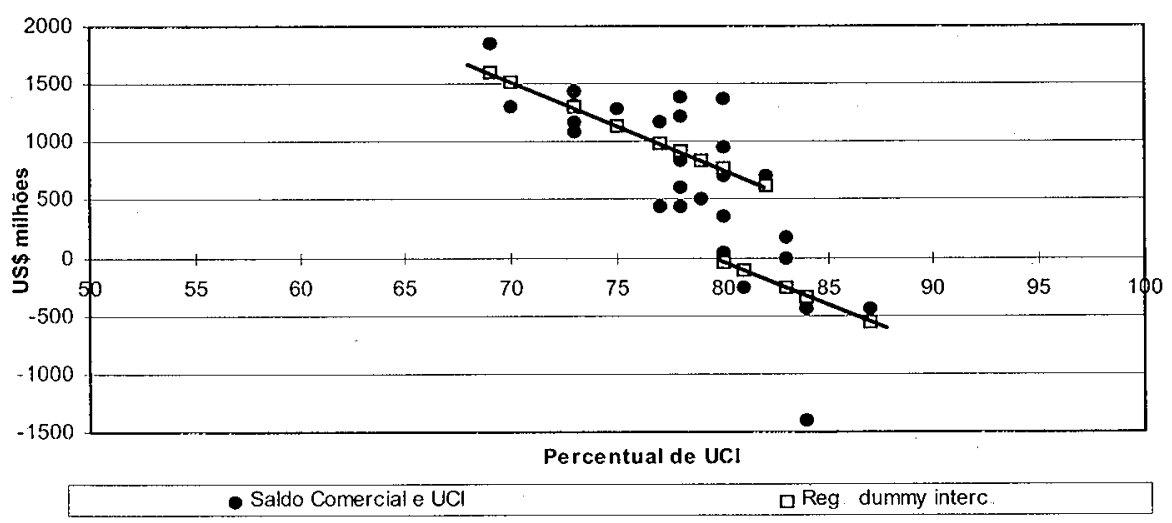

Obs: dados trimestrais dessazonalizados 
Fonte dos dados brutos: Conjuntura Econômica. Sondagem Conjuntural e Conjuntura Estatística, vários números (1980-1997)

Como pode ser visto pelos resultados da regressão, os testes $t$ e valor$P$ validaram a existência dos parâmetros, bem como a inclinação negativa da curva, ao nivel de confiança de $95 \%$. Da mesma forma que se percebeu anteriormente, as inclinações das curvas não podem ser consideradas significativamente diferentes, uma vez que os intervalos de confiança para os parâmetros de inclinação da curva se cruzam. Assim, não se pode creditar à relação UCl versus saldo da Balança Comercial as alterações percebidas nesta última variável no período posterior ao Plano Real, uma vez que a sensibilidade da Balança Comercial em relação à UCl pode ser considerada constante.

O fato da inclusão de dummies de intercepto e inclinação não ter sido válida no modelo não permite que se façam considerações sobre a inclinação da curva no periodo 1995-1996. Em vista disso, o modelo com a dummy de intercepto indica apenas que houve uma queda no patamar do saldo comercial, para os mesmo níveis de $\mathrm{UCl}$.

Considerando os resultados obtidos com as tentativas de inclusão de dummies de inclinação, cabe uma ressalva sobre este tema. A impossibilidade de se utilizar, simultaneamente, dummies de intercepto e inclinação na regressão, verificada pelos testes estatísticos, poderia estar sinalizando para a incapacidade de uma dessas representar as alterações percebidas na série. Se as inclinações das curvas, para os períodos 1980-1983, 19841989 e 1990-1996, não podem ser consideradas diferentes, uma vez que apresentam superposição dos seus intervalos de confiança, parece claro que não houve alterações na elasticidade-UCl do saldo comercial. Dessa forma, pode-se dizer que a variável dummy de inclinação é que afetava negativamente os resultados da regressão que incluía simultaneamente esta e a dummy de intercepto, nos primeiros exercícios realizados.

Por fim, os resultados do coeficiente de correlação apontam para uma capacidade de explicação do modelo da ordem de $74 \%$, indicada pelo Rquadrado ajustado pelo tamanho da amostra, semelhante, portanto, ao do periodo 1980-1983. Porém ressalta-se que, mais importante que os resultados numéricos apontados pelos exercícios, deve-se considerar primordialmente as respostas oferecidas por eles em termos do perfil da relação $\mathrm{UCl}$ versus saldo da Balança Comercial.

\section{CONSIDERAÇÕES FINAIS}

Os exercícios realizados com as regressões através do Método dos Mínimos Quadrados Simples, ainda que tenham apontando poucas respostas sobre os determinantes do saldo da Balança Comercial, foram ex- 
tremamente importantes para que se obtivesse a relação entre esta variável e a UCI da indústria de transformação. Uma vez que o objetivo maior deste trabalho era mostrar a existência da relação entre o saldo comercial e o nivel de $\mathrm{UCl}$ e, se possivel, o sentido e a intensidade desta relação, os resultados alcançados foram satisfatórios.

Através dos parâmetros de inclinação ( $ß \mathrm{UCl})$ das diferentes regressões realizadas, e dos seus respectivos testes, foi possivel mostrar que a tendência é que, a aumentos de $\mathrm{UCl}$ - em função de um aumento de demanda, por exemplo -, correspondam quedas nos resultados da Balança Comercial. Mais que isso, foi possivel mostrar que, entre 1980 e 1996, verificou-se esta relação contrária entre as duas variáveis, ainda que muitas vezes distorcida pelos outros fatores que afetam a Balança Comercial, como controle cambial, barreiras tarifárias e não-tarifárias às importações e estímulos às exportações.

Outra confirmação importante auferida com os exercícios de regressão foram as "quebras" na série 1980-1996. As primeiras regressões - nas quais as variáveis dummies tinham como principal objetivo testar a existência destes deslocamentos - e aquelas realizadas para os períodos considerados mais homogêneos provaram que, de 1980-1983 para 1984-1989, a curva que representa a relação $\mathrm{UCl}$ versus saldo comercial sofreu uma elevação, principalmente em função do efeito conjunto da entrada em funcionamento do projetos do II PND. Os investimentos realizados no âmbito deste Plano promoveram um aumento da capacidade instalada da indústria brasileira que, somados a aumentos de competitividade, criaram um potencial de geração de excedentes exportáveis, que permitiu ao Brasil uma maior gerência sobre a sua política interna, já que os credores internacionais principalmente o FMI - deparavam-se com uma situação menos desconfortável nas contas externas do País.

Não se pode deixar de destacar, porém, outros fatores que influenciaram também este deslocamento descrito anteriormente. As influências administrativas sobre as importações e exportações apontadas acima, o ritmo de crescimento da economia brasileira (a médio e longo prazo) e os períodos de forte demanda internacional (expansão dos mercados), também exerceram pressão, de modo que se verificou uma forte elevação do patamar dos saldos comerciais obtidos pelo Brasil.

Do período 1984-1989 para o período 1990-1996, o que se percebe é um deslocamento da curva para baixo, basicamente em função da abertura comercial, mas também em função da perda de competitividade dos produtos brasileiros no exterior, que já vinha ocorrendo desde 1985, mas que não era sentida em função da expansão do comércio mundial, de acordo com Bonelli (1994). No entanto, a queda do patamar dos saldos comerciais brasileiros não os leva aos mesmos niveis de 1980-1983, ficando a curva 
do período 1990-1996 em uma situação intermediária entre as duas verificadas anteriormente.

A Figura 2, apresentada a seguir, mostra a posição dos períodos em um diagrama, de acordo com os resultados obtidos com o uso das regressões. Como se pode ver, este diagrama inclui também os resultados dos estudos para os períodos considerados homogêneos: 1980-1983, 19841989 e 1990-1996. Cabe ressaltar que a apresentação em formato de diagrama dá uma idéia melhor da posição das curvas de cada período em relação à apresentação dos dados da regressão, como realizado em passagens anteriores do texto. A apresentação do conjunto dos periodos em um só gráfico foi evitada, com o objetivo de não mostrar uma diferença na inclinação das curvas, que estatisticamente não pode ser considerada.

Para o período 1988-1989 foi incluída uma dummy de intercepto, com o intuito de captar os saldos recordes obtidos na Balança Comercial. Na Figura a seguir, fica claro o que poderia ser verificado pelo intercepto das curvas apresentados no Anexo B, ou seja, que este período 1988-1989 foi o que apresentou os maiores patamares de saldo comercial, principalmente em função do crescimento do mercado dos produtos exportáveis brasileiros (Bonelli, 1994).

Para o período 1995-1996 também foi incluída uma dummy de intercepto, com o intuito de captar os efeitos da valorização cambial no modelo. O que se obteve, após testados os parâmetros e verificada a existência do deslocamento da curva para este período, foi uma curva em um patamar mais baixo que para o período 1990-1994, no entanto ainda não no mesmo nivel do início da década de 80.

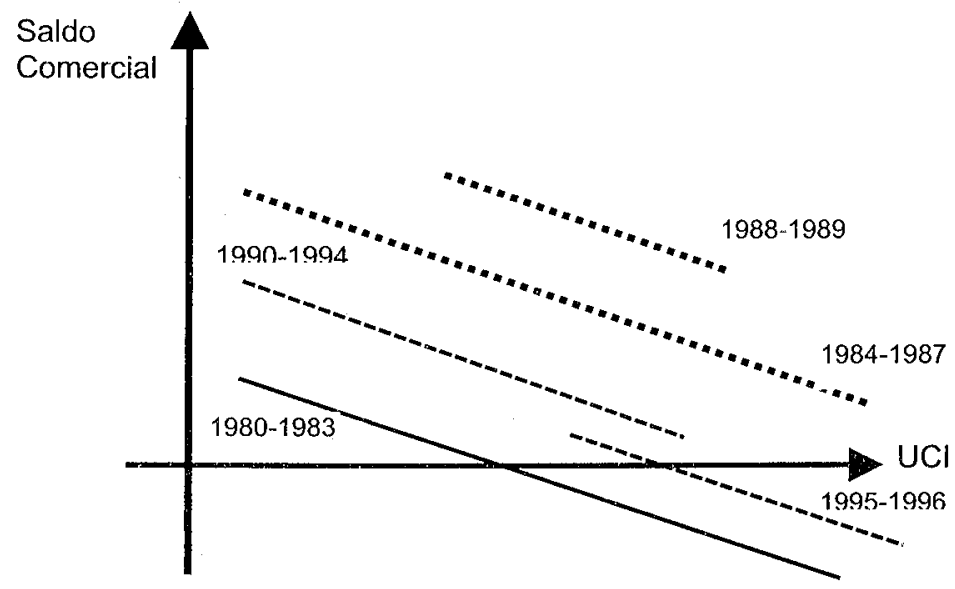

Figura 2 - Diagrama das curvas de UCl versus saldo comercial para diferentes períodos 
Cabe referir novamente a diferença estatisticamente desconsiderável da inclinação das curvas. Uma vez que elas expressariam as variações na sensibilidade do saldo comercial em relação às variações na $\mathrm{UCl}$, e que elas não variaram, pode-se creditar a outros fatores, já referidos no texto, os deslocamentos das curvas ao longo do período.

Em suma, comparando-se os resultados encontrados para estes dois últimos períodos, constatou-se que, para gerar maiores saldos comerciais em 1990-1996, era necessário que se aceitasse uma UCl bem menor que em 1984-1989, o que representaria a promoção de um desaquecimento ou talvez até de uma recessão. Ou, de outra forma, para que fosse possivel aumentar a $\mathrm{UCl}$ e, com isso, promover um incremento da produção, era necessário que se convivesse com saldos comerciais bem menores, e até mesmo negativos. Em linhas gerais, passou-se a trabalhar mais perto do limite da sustentação dos resultados positivos da Balança Comercial, chegando-se mesmo a obter resultados negativos em 1995 e 1996.

Assim, parece que uma alternativa para o caso brasileiro, neste período em que a reestruturação das empresas e os novos investimentos ainda não começam a geraram um maior potencial produtivo, está em substituir o sentido de "usar mais" a planta por "usar melhor". Vários estudos indicam que esta é a alternativa que está sendo adotada, ${ }^{6}$ mais por esforços das empresas do que em decorrência de incentivos do setor público. Dessa forma, enquanto não é possível aumentar a competitividade através de ganhos de escala decorrentes de uma maior utilização da capacidade produtiva, o caminho parece ser o da busca de uma maior eficiência e competitividade com uma escala dada.

\section{BIBLIOGRAFIA}

ABREU, Marcelo de P. (org.). A ordem do progresso: cem anos de política econômica republicana 1889-1989. Rio de Janeiro: Campus, 1989a.

BITTENCOURT, Jeferson L. Os limites para o crescimento econômico brasileiro: uma análise da Balança Comercial pela ótica da capacidade produtiva da indústria. Monografia (graduação em Ciências Econômicas), UFRGS-FCE, 1997

BONELLI, Regis e MALAN, Pedro S. Os limites do possível: notas sobre o balanço de pagamentos e indústria nos anos 70. Pesquisa e Planejamento Econômico. Rio de Janeiro, v.2, n.6, p.353-406, ago. 1976.

BONELLI, Regis. Produtividade, crescimento industrial e exportações de manufaturados no Brasil: desempenho e competitividade. Rio de Janeiro: IPEA, jan. 1994. (Texto para discussão $n$. 327).

CASTRO, Antônio B. de e SOUZA, Francisco E. Pires de. A economia brasileira em marcha forçada. Rio de Janeiro: Paz e Terra, 1985.

\footnotetext{
${ }^{6}$ Nesse sentido ver, por exemplo, Lyra (1996).
} 
CNI (Confederação Nacional da Indústria) e CEPAL (Comissão Econômica para América Latina e o Caribe). Investimentos na indústria brasileira - 1995/1999: caracteristicas e determinantes. Rio de Janeiro: CNI, DEC, 1997, 53 p.

FGV (Fundação Getúlio Vargas): Conjuntura econômica "Conjuntura Estatística, vários números, (1980-1997). Rio de Janeiro: FGV.

Sondagem Conjuntural, vários números (1980-1997). Rio de Janeiro: FGV.

LYRA, Flávio Tavares. A politica industrial brasileira: mudanças e perspectivas. Rio de Janeiro: IPEA, mai. 1996. (Texto para discussão n. ${ }^{\circ}$ 413)

MOREIRA, Mauricio M. e CORREA, Paulo Guilherme. Abertura comercial e indústria: o que se pode esperar e o que se vem obtendo. Rio de Janeiro: BNDES, out. 1996. (Texto para discussão n.49). 
ANEXO A

\section{ANEXOS}

Tabela A1 - Saldo mensal da balança comercial brasileira dessazonalizado1980-1996

(US\$ Milhões)

\begin{tabular}{|c|c|c|c|c|c|c|c|c|c|c|c|c|}
\hline & Jan & $v$. & r. & $r$. & i. & Jun. & dl. & D. & t. & it & v. & $z$ \\
\hline & 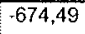 & 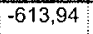 & 7 & 8 & 1 & & 8 & 1 & 9 & $-93,16$ & 0 & 2 \\
\hline & & & 769 & & 9,62 & & & & & & & 33 \\
\hline 26 & $-13,77$ & 1 & 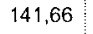 & 17,67 & 8,01 & & 43,70 & 80,80 & 43,10 & 68,40 & & 10 \\
\hline 83 & 216,11 & 264,87 & 1,10 & 524,02 & 1,00 & 15 & 9 & 5,37 & 3,54 & 3 & 5 & 4,47 \\
\hline 84 & 75 & 1342,70 & 1054,11 & 52,60 & 3,34 & 57 & 55,37 & 1149,98 & 029,91 & 1367,97 &, 44 & 421,80 \\
\hline 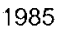 & 728,17 & 741,01 & 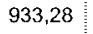 & 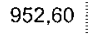 & 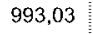 & & 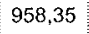 & 52 & 41 & & & 36 \\
\hline 1986 & 964,93 & 1,48 & 178,06 & 1141,71 & 072,38 & 51 & 10 tive & 20 & 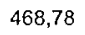 & & & \\
\hline 1987 & $-48,18$ & 489,92 & 57 & 3,61 & 770,22 & 9,94 & 1137,07 & 1120,95 & 1316,64 & 106,89 & 47 & 1704,33 \\
\hline 88 & 41,21 & 73,32 & 1286,38 & 1676,33 & 920,90 & 1879,13 & 4,06 & 1622,99 & 1697,47 & 1852,66 & 2,06 & 2286,18 \\
\hline 1989 & 23,06 & 909 & 1715,53 & 2027 & 12 & 16 & 34 & 6 & 33 & 92 & 66 & 6071 \\
\hline & 692,38 & 021,19 & 684,34 & 1040,09 & 10 & 866,99 & 1159,70 & 758,55 & 673,71 & 487,04 & & 1660,04 \\
\hline & 10 & 569, & 1 & & & & & & 05 & 7 & & 66 \\
\hline & 6 & 2 & 1489,50 & 9 & 50 & 70 & 92 & 56 & 70 & 16 & $1 \stackrel{1}{\frac{3}{3}}$ & 77 \\
\hline 15 & 6 & 2244,47 & 1570,74 & 797,96 & 1064,37 & & 509,61 & & 5 & 4 & & 1304,21 \\
\hline 1 & 23 & 45,20 & 1147,85 & 131 & 13 & 953,92 & 95 & 36 & 13 & 77 & ,38 & 49 \\
\hline 1 & $-418,46$ & $-1624,40$ & $-960,36$ & 33 & & $-b 0$ & 0,78 & 10 & 422,17 & 393,88 & 18,83 & $-79,41$ \\
\hline 1996 & 48,18 & $-33,68$ & -4 & 7 & 0 & 31 & -260 & 27 & 98 & 1543,68 & $-1070,70$ & 272 \\
\hline
\end{tabular}

Fonte: Conjuntura Econômica. Conjuntura Estatística, vários números (1980-1997) - FGV.

Tabela A2 - Utilização da capacidade instalada da indústria da transformação brasileira, com ajuste sazonal 1980/96(\%)

\begin{tabular}{l|r|r|r|r}
\hline & Janeiro & Abril & Julho & Outubro \\
\hline 1980 & 85 & 85 & 85 & 83 \\
1981 & 83 & 79 & 76 & 73 \\
1982 & 75 & 77 & 77 & 75 \\
1983 & 74 & 75 & 72 & 72 \\
1984 & 73 & 75 & 74 & 75 \\
1985 & 78 & 78 & 77 & 79 \\
1986 & 82 & 82 & 82 & 85 \\
1987 & 85 & 84 & 76 & 79 \\
1988 & 80 & 81 & 79 & 79 \\
1989 & 79 & 80 & 83 & 82 \\
1990 & 80 & 61 & 77 & 78 \\
1991 & 69 & 75 & 78 & 77 \\
1992 & 70 & 73 & 73 & 73 \\
1993 & 73 & 78 & 79 & 78 \\
1994 & 78 & 80 & 80 & 82 \\
1995 & 84 & 87 & 83 & 80 \\
1996 & 80 & 83 & 81 & 84 \\
\hline
\end{tabular}


FONTE: Conjuntura Econômica Sondagem Conjuntural, vários números (1980-1996) FGV

ANEXO B

Resumo dos resultados para o período 1980-1996

\begin{tabular}{lr}
\hline & Estatistica de regressão \\
\hline R múltiplo & 0,772 \\
R-Quadrado & 0,596 \\
R-quadrado ajustado & 0,577 \\
Erro padrão & 457,468 \\
Observações & 68 \\
\hline
\end{tabular}

\begin{tabular}{lrrrrrr}
\hline & gl & \multicolumn{1}{c}{ SQ } & \multicolumn{1}{c}{ MQ } & \multicolumn{1}{c}{ F } & F de Significação \\
\hline Regressão & 3 & 19727032,38 & 6575677,46 & 31,42091908 & $1,31701 \mathrm{E}-12$ \\
Residuo & 64 & 13393731,62 & 209277,06 & & \\
Total & 67 & 33120764 & & & & \\
\hline
\end{tabular}

\begin{tabular}{lrrrrrrrr}
\hline & Coefic & Erro pad & Stat t & valor-P & \multicolumn{1}{c}{$95 \%$ infer } & $95 \%$ super & Infer. 95,0\% & Super. 95,0\% \\
\hline Interseção & 6376,59 & 961,64 & 6,63 & $8,23 E-09$ & 4455,5043 & 8297,6827 & 4455,5043 & 8297,6827 \\
D1 intercepto & 1176,77 & 148,92 & 7,90 & $4,80 E-11$ & 879,2753 & 1474,2704 & 879,2753 & 1474,2704 \\
D2 intercepto & 604,79 & 143,39 & 4,22 & $7,92 E-05$ & 318,3292 & 891,2572 & 318,3292 & 891,2572 \\
UCIX & $-81,20$ & 12,26 & $-6,62$ & $8,51 E-09$ & $-105,6924$ & $-56,7048$ & $-105,6924$ & $-56,7048$ \\
\hline
\end{tabular}

\section{Resumo dos resultados para o período 1980-1994}

\begin{tabular}{lr}
\hline & \\
\hline$R$ múltiplo & Estatística de regressão \\
R-Quadrado & 0,808 \\
R-quadrado ajustado & 0,653 \\
Erro padrão & 0,634 \\
Observações & 380,150 \\
\hline
\end{tabular}

\begin{tabular}{lrrrrr}
\hline & gl & SQ & MQ & F & F de significação \\
\hline Regressão & 3 & 15227260,67 & 5075753,55 & 35,12286758 & $6,6602 \mathrm{E}-13$ \\
Residuo & 56 & 8092795,913 & 144514,21 & & \\
Total & 59 & 23320056,58 & & & \\
\hline
\end{tabular}

\begin{tabular}{|c|c|c|c|c|c|c|c|c|}
\hline & Coef. & Erro pad. & Stat t & valor-P & $95 \%$ infer. & $95 \%$ super. & Infer. $95,0 \%$ & Super. $95,0 \%$ \\
\hline Interseçäo & 4146,51 & 914,02 & 4,54 & $\begin{array}{r}3,06 \mathrm{E}- \\
05 \\
1,16 \mathrm{E}-\end{array}$ & 2315,5034 & 5977,5138 & 2315,5034 & 5977,5138 \\
\hline D1 intercepto & 1131,43 & 124,08 & 9,12 & $\begin{array}{r}12 \\
1,12 \mathrm{E}\end{array}$ & 882,8748 & 1379,9879 & 882,8748 & 1379,9879 \\
\hline $\mathrm{D} 2$ intercepto & 871,57 & 130,24 & 6,69 & $\begin{array}{r}08 \\
3,45 E-\end{array}$ & 610,6646 & 1132,4787 & 610,6646 & 1132,4787 \\
\hline $\mathrm{UCIX}$ & $-52,56$ & 11,67 & $-4,50$ & 05 & $-75,9466$ & $-29,1772$ & $-75,9466$ & $-29,1772$ \\
\hline
\end{tabular}

Resumo dos resultados para o período 1980-1983

Estatística de regressão

$\mathrm{R}$ múltiplo

$0, \overline{883}$ 
R-Quadrado

0,779

R-quadrado ajustado

Erro padrão

Observações

\begin{tabular}{lrrrrr}
\hline & gl & \multicolumn{1}{c}{ SQ } & \multicolumn{1}{c}{ MQ } & F & F de significação \\
\hline Regressão & 1 & 1533093,50 & 1533093,51 & 49,45172415 & $5,93803 \mathrm{E}-06$ \\
Resíduo & 14 & 434025,50 & 31001,82 & & \\
Total & 15 & 1967119 & & & \\
\hline
\end{tabular}

\begin{tabular}{lrrrrrrrr}
\hline & Coefic. & \multicolumn{1}{c}{ Erro pad. } & Stat $\mathrm{t}$ & valor-P & $95 \%$ infer. & $95 \%$ super. & Infer. 95,0\% & Super. 95,0\% \\
\hline Interseção & 5253,94 & 740,86 & 7,09 & $5,41 E-06$ & 3664,9451 & 6842,9364 & 3664,9451 & 6842,9364 \\
UCIX & $-66,78$ & 9,50 & $-7,03$ & $5,94 \mathrm{E}-06$ & $-87,1509$ & $-46,4142$ & $-87,1509$ & $-46,4142$ \\
\hline
\end{tabular}

\section{Resumo dos resultados para o período 1984-1989}

\begin{tabular}{lr}
\hline & Estatistica de regressão \\
\hline R múltiplo & 0,791 \\
R-Quadrado & 0,626 \\
R-quadrado ajustado & 0,591 \\
Erro padrão & 333,7 \\
Observações & 24 \\
\hline
\end{tabular}

\begin{tabular}{lrrrrr}
\hline & gl & SQ & MQ & F & F de significação \\
\hline Regressão & 2 & 3920896,95 & 1960448,48 & 17,60759104 & $3,23474 \mathrm{E}-05$ \\
Resíduo & 21 & 2338163,01 & 111341,10 & & \\
Total & 23 & 6259059,96 & & & \\
\hline
\end{tabular}

\begin{tabular}{|c|c|c|c|c|c|c|c|c|}
\hline & Coef. & Erro pad. & Stat $t$ & valor-P & $95 \%$ infer. & $95 \%$ super. & Infer, $95,0 \%$ & Super. $95,0 \%$ \\
\hline Interseção & 7554,70 & 1676,40 & 4,51 & $\begin{array}{r}1,94 E- \\
04\end{array}$ & 4068,4430 & $\begin{array}{r}11040,960 \\
4\end{array}$ & 4068,4430 & 11040,9604 \\
\hline vCI $x$ & $-84,37$ & 21,19 & $-3,98$ & $\begin{array}{r}6,80 E- \\
04\end{array}$ & $-128,4448$ & $-40,2945$ & $-128,4448$ & $-40,2945$ \\
\hline$D$ intercepto & 751,88 & 147,40 & 5,10 & $\begin{array}{r}4,72 E- \\
05\end{array}$ & 445,3557 & 1058,4109 & 445,3557 & 1058,4109 \\
\hline
\end{tabular}

\section{Resumo dos resultados para o periodo 1990-1996}

\begin{tabular}{lr}
\hline & Estatística de regressão \\
\hline R múltiplo & 0,875 \\
R-Quadrado & 0,765 \\
R-quadrado ajustado & 0,745 \\
Erro padrão & 372,637 \\
Observações & 27 \\
\hline
\end{tabular}

\begin{tabular}{lrrrrr}
\hline & gl & \multicolumn{1}{c}{ SQ } & \multicolumn{1}{c}{ MQ } & \multicolumn{1}{c}{$F$} & F de significação \\
\hline Regressão & 2 & 10840898,40 & 5420449,20 & 39,03586584 & 2,85541 E-08 \\
Residuo & 24 & 3332596,27 & 138858,18 & & \\
Total & 26 & 14173494,67 & & & \\
\hline
\end{tabular}




\begin{tabular}{|c|c|c|c|c|c|c|c|c|}
\hline & Coefic. & Erro pad. & Stat t & valor $-P$ & $95 \%$ infer. & $95 \%$ super. & Infer. $95,0 \%$ & Super. $95,0 \%$ \\
\hline Interseção & 6800,98 & 1721,56 & 3,95 & $\begin{array}{r}5,97 \mathrm{E}- \\
04\end{array}$ & 3247,8533 & $\begin{array}{r}10354,115 \\
3\end{array}$ & 3247,8533 & 10354,1153 \\
\hline D intercepto & $-802,92$ & 212,86 & $-3,77$ & $\begin{array}{r}9,35 \mathrm{E} \\
04\end{array}$ & 1242,2462 & $-363,5974$ & 1242,2462 & $-363,5974$ \\
\hline UCIX & $.75,41$ & 22,52 & $-3,35$ & $\begin{array}{r}2,67 E- \\
03\end{array}$ & $-121,8759$ & $-28,9383$ & $-121,8759$ & $-28,9383$ \\
\hline
\end{tabular}

